(C) Elsevier/INRA

Original article

\title{
Adaptative significance of amylase polymorphism in Drosophila. III. Geographic patterns in Drosophila subobscura tissue-specific expression of amylase in adult midgut
}

\author{
M Andjelković*, M Stamenković-Radak, M Sekulic, M Milanović \\ University of Belgrade, Institute of Biological Research, 29 Novembra 142, \\ 11000 Belgrade, Yugoslavia
}

(Received 8 March 1990; accepted 10 March 1991)

\begin{abstract}
Summary - Eight natural populations of D subobscura (Collin) were studied for genetically controlled variation in tissue-specific expression of $\alpha$-amylase enzyme. Polymorphism for amylase tissue variation in the midgut was found to be present in natural populations. This type of phenotypic variability showed intra- and interpopulation variability. The geographic variation in $\alpha$-amylase midgut activity patterns of gene expression was found to be uncorrelated with allozyme variation at the structural locus. There was no detectable correlation of activity patterns in the anterior midgut with those in the posterior midgut.
\end{abstract}

Drosophila subobscura / $\alpha$-amylase / tissue-specific expression / inter- and intrapopulation variability

Résumé - Signification adaptive du polymorphisme de l'amylase chez Drosophila. III. Variation géographique de l'expression de l'amylase dans l'intestin moyen de l'adulte de Drosophila subobscura. Huit populations naturelles de Drosophila subobscura ont été étudiées et se sont révélées polymorphes pour l'expression tissulaire de l'amylase $\alpha$ dans l'intestin moyen. Il existe un polymorphisme intra- et interpopulationnel. Il n'existe pas de corrélation entre l'activité amylasique dans la partie antérieure et postérieure de l'intestin moyen, pas plus qu'avec le polymorphisme au locus structural.

Drosophila subobscura / amylase $\alpha$ / expression tissulaire / variabilité inter- et intrapopulation

\footnotetext{
* Correspondence and reprints
} 


\section{INTRODUCTION}

A number of authors have suggested that changes in genetic regulation are of major importance in eukaryotic evolution (for references see Hedrick and McDonald, 1980 ; Templeton, 1981; McIntyre, 1982; Paigen, 1986). Many tissue-specific enzyme pattern differences may be due to the effect of variants at regulatory loci. One of the most extensively studied regulatory gene systems, that affects a tissue-specific enzyme pattern is $\alpha$-amylase expression in Drosophila (Powell and Lichtenfels, 1979; Doane, 1980; Powell et al, 1980).

We have started to study intensively Drosophila subobscura for genic and phenotypic polymorphism of $\alpha$-amylase and its tissue-specific expression in adult midgut; hence, in the present paper the geographic variation of these types of polymorphism is presented.

\section{MATERIALS AND METHODS}

An analysis of tissue-specific midgut $\alpha$-amylase activity pattern (MAP-type) was undertaken in $D$ subobscura adults from 8 natural populations (details on these collections are given in Andjelković et al, 1987). All flies were reared on standard cornmeal-sugar-agar-yeast food medium for one generation before determining midgut amylase activity. First generation fresh sampled flies from nature were studied.

The method described by Abraham and Doane (1978) was used to prepare dissected midguts of 3-5 d-old adults and to determine their amylase activity. The activity could be expressed in 3 regions of the anterior (AMG) and 2 regions of the posterior ( $P M G$ ) midgut. The presence of activity is indicated by a number and absence by zero (eg, 12310 means activity in the 3 regions of AMG and region 1 of PMG, but absence of activity in region 2 of PMG).

The range of intrapopulation phenotypic variability is given by Shannon's diversity index and for testing the significance of differences in phenotypic, frequency distributions between populations $I$-divergence analysis was used, derived from Shannon's entropy function (Orloci, 1970), given by :

$$
I=\sum \sum f_{i j} \ln \frac{f_{. . f_{i j}}}{f_{i \cdot f_{\cdot j}}}
$$

In this expression $f_{j .}, f_{. j}$ and $f .$. signify the $i$ th phenotype (row) total, the $j$ th locality (column) total, and the grand total for all phenotypes (or all localities), respectively. The number of species is $r$. Twice the value of $I$ is an approximation to $\chi^{2}$ with $(r-1)(c-1)$ degrees of freedom. 


\section{RESULTS}

Table I presents the frequencies of midgut activity pattern (MAP-types) in 8 natural populations of $D$ subobscura. In the data both sexes were combined, since no significant differences have been detected between male and female patterns (Stamenković-Radack et al, 1987).

The number of theoretically possible patterns of amylase midgut activity in $D$ subobscura is 32, but the MAP-type AMG-000 PMG-00 has not been detected so far. Other midgut activity patterns occurred with different frequencies in populations analyzed in this paper. In 7 of them, the most frequent MAP-type was AMG-123 PMG-12, whose frequency was in the range from $33.3-62.6 \%$. In the Kužni Do population, the most frequent MAP-type was AMG-100 PMG-00 (34.7\%). Except for those 2 MAP-types, all others appeared with lower frequencies in populations studied. There were 5 MAP-types $(12310,12300,12012,12000$, 100 10), with frequency of $5 \%$ and higher, in some populations and 3 MAP-types $(12300,12012,10012)$, which occurred only in a number of populations with a frequency of $10 \%$ and higher.

As the genotypes of different MAP types were not known, it was not possible to estimate gene frequencies or gene heterozygosity. Therefore, the Shannon diversity measure (diversity index) was used. The value of $H$ showed that there were differences in the degree of polymorphism between the populations. These differences reached a ratio as great as 1.7 in the case of the Popovica population (the highest $H$ value) with respect to the Zürich population (the lowest $H$ value).

Because it was impossible to test the statistical significance of diversity index differences, we tested the significance of the difference in phenotypic frequency distribution among population applying the $I$-divergence analysis (Orloci, 1970). The analysis showed (table II) that significant differences in the type of diversity existed between the populations Popovica. Ravnište and Kužni Do, as well as between each of these populations and all the others. Statistically significant differences were also found between the Pomena populations and all others except Zürich and Raices. Shannon's index mainly represents qualitative variability according to the number of classes involved. On the other hand, the normalized Shannon's index $(R)$ (Legendre and Legendre, 1983), better reflects quantitative variability according to the frequency of certain phenotypes. These values are given in table I, as well. The relations obtained were similar to the values of Shannon's indices of diversity, although certain discrepancies existed. The highest $R$ value belonged to the Kužni Do population, which was the result of the fact that the frequencies of several phenotypes were nearly equal and relatively high.

Considering that the total number of amylase active regions in the midgut has a certain biological significance in a sense of phenotypic expression, we classified the phenotypes obtained according to that (NAR). The analysis showed a statistically significant difference $\left(\chi^{2}=303.094, d f=28, P<0.001\right)$, as the midgut patterns with varying number of active regions were differently represented in populations studied (table III). 


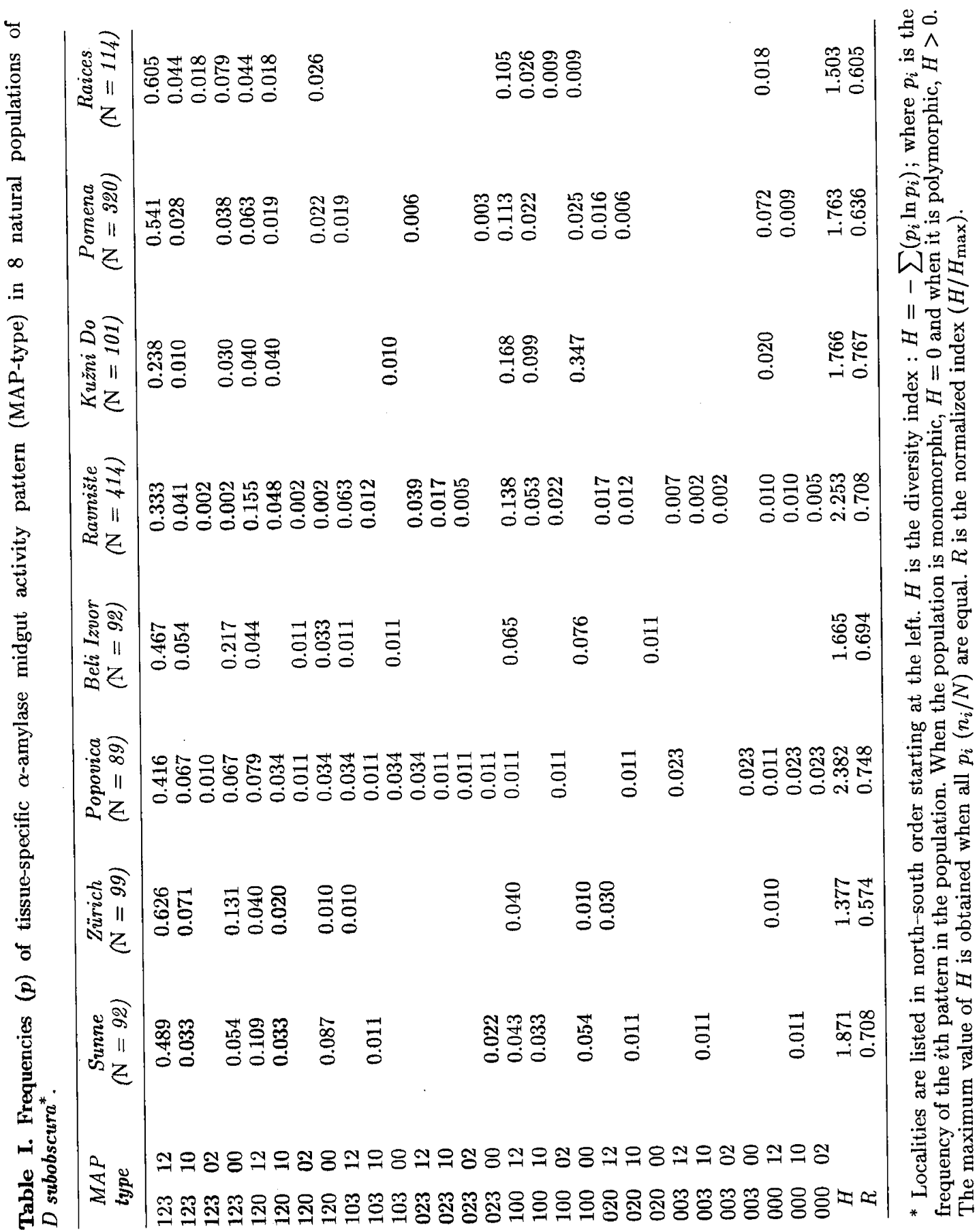


Table II. Comparisons of pairs of populations using independence components test ( $I$ - divergence).

\begin{tabular}{lcclcccc}
\hline & Zürich & Popovica & Beli Izvor & Ravnište & Kužni Do & Pomena & Raices \\
\hline Sunne & \multirow{2}{*}{39.159} & $48.929^{*}$ & 38.121 & $104.195^{*}$ & $71.941^{*}$ & $43.434^{*}$ & 31.006 \\
Zürich & & $49.661^{*}$ & 24.019 & $117.546^{*}$ & $101.795^{*}$ & 36.849 & 19.930 \\
Popovica & & & $56.918^{*}$ & $85.206^{*}$ & $123.643^{*}$ & $86.278^{*}$ & $57.038^{*}$ \\
Beli Izvor & & & & $78.385^{*}$ & $78.385^{*}$ & $66.618^{*}$ & 34.636 \\
Ravnište & & & & & $182.482^{*}$ & $154.827^{*}$ & $103.450^{*}$ \\
Kužni Do & & & & & & $116.520^{*}$ & $84.085^{*}$ \\
Pomena & & & & & & & 30.939 \\
\hline
\end{tabular}

* $P<0.05$.

Table III. Frequencies of $\alpha$-amylase active in the midgut of the 8 natural populations of D subobscura.

\begin{tabular}{ccccccccc}
\hline NAR & Sunne & Zürich & Popovica & Beli Izvor & Ravnište & Kužni Do & Pomena & Raices \\
\hline 5 & 0.489 & 0.626 & 0.416 & 0.467 & 0.333 & 0.238 & 0.541 & 0.605 \\
4 & 0.141 & 0.121 & 0.225 & 0.109 & 0.300 & 0.050 & 0.116 & 0.105 \\
3 & 0.141 & 0.222 & 0.180 & 0.294 & 0.294 & 0.238 & 0.184 & 0.202 \\
2 & 0.163 & 0.020 & 0.112 & 0.044 & 0.104 & 0.129 & 0.125 & 0.079 \\
1 & 0.065 & 0.010 & 0.067 & 0.087 & 0.015 & 0.347 & 0.034 & 0.009 \\
$H$ & 1.377 & 1.008 & 1.436 & 1.305 & 1.370 & 1.463 & 1.270 & 1.106 \\
\hline
\end{tabular}

$N A R=$ number of active regions.

Table IV presents $H$ values for several forms of amylase polymorphism in $D$ subobscura amylase structural gene $\left(H_{\mathrm{AMY}}\right)$, MAP-types $\left(H_{\mathrm{MAP}}\right)$, number of active regions $\left(H_{\mathrm{NAR}}\right)$, MAP-types for AMG $\left(H_{\mathrm{AMG}}\right)$ and for PMG $\left(H_{\mathrm{PMG}}\right)$ separately. The correlations between these diversity indices were not statistically significant.

Table IV. The diversity index $H$ of : $A m y$ alleles $\left(H_{\mathrm{AMY}}\right)$, midgut activity patterns in the whole midgut $\left(H_{\mathrm{MAP}}\right)$, total number of active regions in the midgut ( $\left.H_{\mathrm{NAR}}\right)$, midgut patterns of the AMG region $\left(H_{\mathrm{AMG}}\right)$ and midgut patterns of the PMG region ( $\left.H_{\mathrm{PMG}}\right)$, for $8 \mathrm{D}$ subobscura populations. The correlation coefficients between the diversities are given at the lower part of the table, critical value of $P=0.05$ is 0.707 ; $d f=6$.

\begin{tabular}{lcccccccc}
\hline & \multicolumn{1}{c}{ Localities } \\
& Sunne & Zürich & Popovica & Beli Izvor & Ravnište & Kužni Do & Pomena & Raices \\
\hline$H_{\mathrm{AMY}}{ }^{*}$ & 0.761 & 1.063 & 0.824 & 0.860 & 1.055 & 0.930 & 0.925 & 1.049 \\
$H_{\mathrm{MAP}}$ & 1.871 & 1.377 & 2.345 & 1.664 & 2.253 & 1.767 & 1.763 & 1.503 \\
$H_{\mathrm{NAR}}$ & 1.377 & 1.008 & 1.436 & 1.305 & 1.370 & 1.463 & 1.270 & 1.106 \\
$H_{\mathrm{AMG}}$ & 1.200 & 0.693 & 1.434 & 0.845 & 1.633 & 0.979 & 1.236 & 0.787 \\
$H_{\mathrm{PMG}}$ & 0.893 & 0.714 & 1.076 & 0.888 & 0.679 & 1.007 & 0.578 & 0.757 \\
\hline
\end{tabular}

MAP:AMY $r=+0.3533$; NAR:AMY $r=-0.6262$; AMG:AMY $r=-0.2247$; PMG:AMY $r=-0.6020 ;$ AMG:PMG $r=+0.0191 .{ }^{*}$ From data of Andjelković et al (1987). 


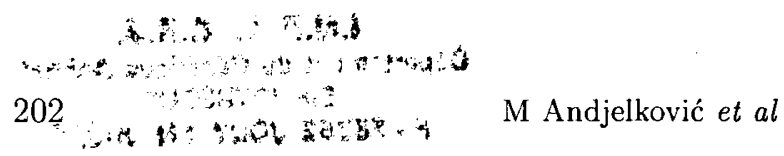

\section{DISCUSSION}

Recent investigations have shown that variation in gene regulation is widespread in natural populations, although the evidence is limited to a few gene-enzyme systems (McIntyre, 1982). The variation in the regulation of $\alpha$-amylase activity in Drosophila midgut is one such example.

Our results primarily showed that 29 detected MAP-phenotypes were not equally distributed among $D$ subobscura populations (table I). The results on $D$ pseudoobscura (Powell and Andjeljković, 1983; Powell and Amato, 1984) and on $D$ melanogaster (Klarenberg et al, 1987) clearly reveal that different midgut activity phenotypes show selective differences in laboratory populations maintained on media with different starch concentrations. The results of Marinković et al (1984) on $D$ subobscura have shown that there is a correlation between MAP-types and pre-adult developmental rate. All this confirms the assumption that intra- and interpopulation polymorphism for the tissue-specific expression of $\alpha$-amylase in $D$ subobscura adult midguts is probably controlled by selection. The absence of correlation among the activity patterns in the AMG and PMG gives evidence that these 2 midgut activity subpatterns are at least separately determined (Stamenković-Radak et al, 1987).

Natural populations of $D$ subobscura are highly polymorphic for inversions in every chrosomome, with certain temporal and spatial patterns (Krimbas and Loukas, 1980). Different alleles could be associated with different gene arrangements and gives direct evidence in support of the coadaptation hypothesis, as has been shown for several Drosophila species (Sperlich and Pfriem, 1986). Such association could be responsible for the lack of correlation with geographic variation in $\alpha$-amylase midgut activity pattern obtained in this paper, but this should be the subject of further investigations of different kind and approach.

A question arises of whether there could be any kind of correlation between the 2 types of polymorphism, ie whether the degree of polymorphic variability of gene regulation (MAP) varies independently of that of the structural gene polymorphism in the natural $D$ subsobscura populations under study. A similar phenomenom was observed in some other Drosophila species (Powell, 1979; Powell et al, 1980). However, Klarenberg and Scharloo (1986) demonstrated linkage disequilibrium between $A m y$ and map in $D$ melanogaster populations of different geographic origin.

Besides these, laboratory studies on Drosophila $A m y$ variants exist, which detect selective pressures on gene-structural polymorphism level (De Jong and Scharloo, 1976; Scharloo et al, 1977; Hickey and Benkel, 1982; Powell and Andjelković, 1983). Considering these data, the absence of correlation between these 2 types of polymorphism could not be explained by their adaptive neutrality. A possible explanation could be that both polymorphisms are controlled by selection, but are not under the influence of the same evolutionary-ecological forces.

\section{ACKNOWLEDGMENTS}

We thank B Jelisavčić for excellent technical assistance. This work was supported by the National Scientific Foundation (contrat $\mathrm{N}^{\circ} 8106$ ). 


\section{I.N.R.A. C.R.J.

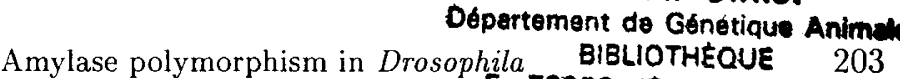 \\ 78352 JOUY EN JOSAS}

\section{REFERENCES}

Abraham I, Doane WW (1978) Genetic regulation of tissue-specific expression of amylase structural genes in Drosophila melanogaster. Proc Natl Acad Sci USA 75, 4446-4450

Andjelković M, Milanović M, Stamenković-Radak M (1987) Adaptive significance of amylase in Drosophila. I. The geographical pattern of allozyme polymorphism at the amylase locus in Drosophila subobscura. Genetica 74, 161-171

De Jong GA, Scharloo W (1976) Environmental determination of selective significance or neutrality of amylase variants in Drosophila melanogaster. Genetics 84, 77-94

Doane WW (1980) Midgut amylase activity patterns in Drosophila; nomenclature. Drosophila Inf Serv 55, 36-39

Hedrick PW, McDonald JF (1980) Regulatory gene adaptation : an evolutionary model. Heredity 45, 83-97

Hickey DA, Benkel B (1982) Regulation of amylase activity in Drosophila melanogaster: effects of dietary carbohydrate. Biochem Genet 20, 1117-1129

Klarenberg JA, Scharloo W (1986) Nonrandom association between structural Amy and regulatory map variants in Drosophila melanogaster. Genetics 114, 875-884

Klarenberg JA, Sikkema K, Scharloo W (1987) Functional significance of regulatory map and structural Amy variants in Drosophila melanogaster. Heredity 58, 383-389 Krimbas CB, Loukas M (1980) The inversion polymorphism of $D$ subobscura. In : Evolutionary Biology (Hecht MK, Steere WC, Wallace B, eds) vol 12, Plenum Press New York, 163-233

Legendre L, Legendre P (1983) Numerical Ecology Elsevier Sci Publ Co, Amsterdam McIntyre RJ (1982) Regulatory genes and adaptation; past, present and future. In : Evolutionary Biology (Hecht MK, Wallace B, Prance GT, eds) Evol Biol 15, 247-285

Marinković M, Milošević M, Andjelković M (1984) Regulatory polymorphism in midgut $\alpha$-amylase activity and developmental rate of Drosophila subobscura. Genetica 64, 115-122

Orloci L (1970) Analysis of vegetation samples based on the use of information. $J$ Theor Biol 29, 173-189

Paigen K (1986) Gene regulation and its role. In : Evolutionary Processes and Theory (Karlin S, Nevo E, eds) Academic Press Inc, Orlando FL, 3-36

Powell JR, Lichtenfels J (1979) Population genetirs of Drosophila amylase. I. Genetic control of tissue-specific expression in $D$ pseudoobscura. Genetics 92 , 603-612

Powell JR (1979) Population genetics of Drosophila amylase. II. Geographic patterns in $D$ pseudoobscura. Genetics $92,613-622$

Powell JR, Rico M, Andjelković M (1980) Population genetics of Drosophila amylase. III. Interspecific variation. Evolution 34, 209-213

Powell JR, Andjelković M (1983) Population genetics of Drosophila amylase. IV. Selection in laboratory populations maintained on different carbohydrates. Genetics 103, 675-689

Powell JR, Amato GD (1984) Population genetics of Drosophila amylase. V. Genetic background and selection on different carbohydrates. Genetics 106, 625-629 
Scharloo W, Van Dijken RF, Hoorn WJA, De Jong G, Thoring WEG (1977) Functional aspects of genetic variation. In : Measuring Selection in Natural Populations. Lecture Notes In Biomathematics (Cristiansen FB, Fenchel TM eds) SpringerVerlag, Berlin, 131-147

Sperlich D, Pfriem P (1986) Chromosomal polymorphism in natural and experimental populations. In : The Genetics and Biology of Drosophila. (Ashburner M, Carson HL, Thompson JN, eds), Academic Press Inc London, vol 3, 257-309 Stamenković-Radak M, Andjelković M, Milošević M (1987) Adaptive significance of allozyme polymorphism in Drosophila. II. The characteristics of polymorphism of $\alpha$-amylase tissue-specific expression in D subobscura. Arch Biol Sci (Yugoslavia) $39,1-4$

Templeton AR (1981) Mechanisms of speciation - a population genetic approach. Annu Rev Ecol Syst 12, 23-48 